Viewpoint

\title{
A Framework for Ecotoxicity Testing in the 21st Century: Ecotox 21
}

\author{
Zhen-guang Yan $₫$, Xin Zheng *, Fu Gao, Jun-tao Fan, Shu-ping Wang and Li-xin Yang
}

State Key Laboratory of Environmental Criteria and Risk Assessment, Chinese Research Academy of Environmental Sciences, Beijing 100012, China; zgyan@craes.org.cn (Z.-g.Y.); gaofugaofu@126.com (F.G.); fanjt@craes.org.cn (J.-t.F.); wangsp@craes.org.cn (S.-p.W.); yanglx@craes.org.cn (L.-x.Y.)

* Correspondence: zhengxin@craes.org.cn; Tel.: +86-10-84915174

Received: 24 December 2018; Accepted: 17 January 2019; Published: 28 January 2019

\begin{abstract}
To reduce the considerable investments of toxicity testing and protecting animal welfare, a new toxicity testing strategy based on response pathways of human cell lines has been proposed in the United States to evaluate the chemical exposure risks to human health. However, the in vitro high-throughput assays have not yet been fully applied in ecotoxicity testing. This paper proposes a framework for high-efficiency ecotoxicity testing strategies to evaluate the ecological risk of chemicals. It consists of pathway-based toxicity testing, embryo-based toxicity testing, and predictive toxicology and data extrapolation, etc., according to different situations. The results of ecotoxicity testing or data mining are analyzed together with physicochemical properties, environmental fate, and exposure data of chemicals to conduct a comprehensive risk assessment of chemicals. The framework provides valuable points to establish high-efficiency ecotoxicity testing strategies in the 21st century.
\end{abstract}

Keywords: framework; ecotoxicity testing; high-throughput assay; ecological risk assessment

Toxicity testing serves as an important approach to evaluate the health effects of chemicals. However, conventional animal-based tests are constrained by the considerable investments of animals, time, and capitals. Meanwhile, using in vivo animal tests to extrapolate human health predictions remains controversial due to a number of assumptions requiring scrutiny. As articulated in the 2007 National Research Council (NRC) report, a new toxicity testing strategy based on response pathways of human cell lines was proposed by the National Institute of Environmental Health Sciences (NIEHS) and the U.S. Environmental Protection Agency (US EPA) [1]. It envisioned a pathway-based foundation to evaluate risks of the chemical exposure. Scientists are attaching increasing importance to this approach [2]. To date, several new initiatives began to refine information from toxicity pathway tests for use in safety evaluations of substances [3].

High-throughput screening assays based on cellular response pathways are generally expected as the future of toxicity testing. As knowledge continues to evolve, all routine toxicity testing could finally be conducted in cells or cell lines. This approach arose in the area of toxicology over the last decade, but was mainly used to assess the health effects of toxicants. Chemical exposures not only pose threats to human well-being, but also damage the ecosystems with adverse effects on fish, birds, and other wild organisms. In this case, ecotoxicity testing is also at a pivotal juncture in identifying toxic substances and assessing risks of chemical exposures. However, the in vitro high-throughput assays have not yet been fully applied in the ecotoxicity testing.

The ecotoxicity testing herein differs from the toxicity testing above, and it focuses upon effects of stressors on wild species rather than human well-being. Species vary from one another, and their sensitivities to environmental agents are significantly different. In high-throughput toxicity tests for human health assessments, cell lines of human origin are used to substitute laboratory animals. 
Similarly, cell lines of wild species are in demand for ecotoxicity tests. Nevertheless, cell lines of the most species have not been established, which results in the limitation of applying high-throughput screening assays. The current vision proposes a new framework which is expected to advance the ecotoxicity testing in the 21st century (Figure 1).

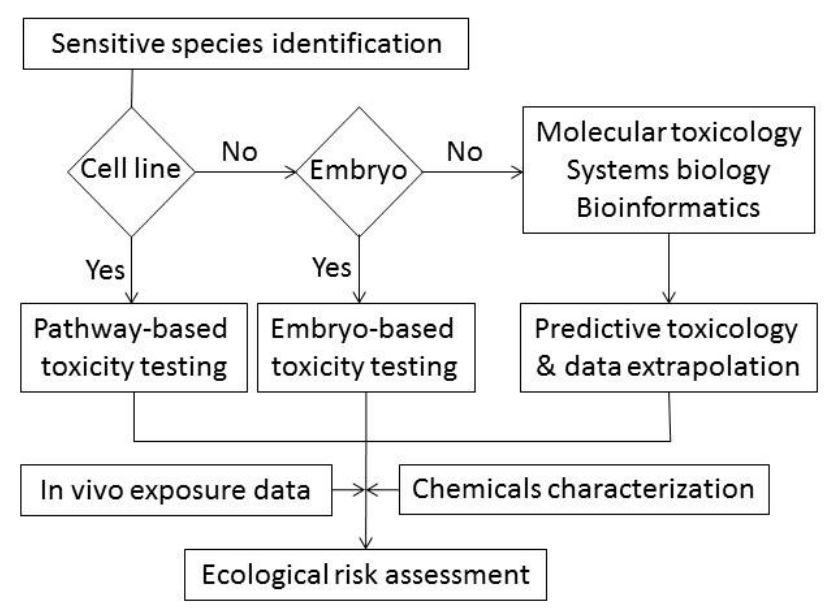

Figure 1. A framework for ecotoxicity testing in the 21st century.

As illustrated in Figure 1, sensitive species should be initially identified through published individual ecotoxicity data analysis. Biological responses are significantly altered by both chemicals and species, which lead to the diversity of species sensitivity [4]. Each species may display a high susceptibility to certain chemicals. Matching up pairs of "sensitive species-chemicals" provides a basis for the next step of ecotoxicity testing. Preliminary trials were initiated in this field [5-10]. The in vivo exposure data of chemical are obtained from various database (e.g., ECOTOX) and other published literatures. Then, based on the data, species sensitivity distribution (SSD) was applied to find the sensitive species to a certain chemical. With results of ecotoxicity data analysis at the individual level, Chinese researchers compiled an extensive list of native sensitive species. Such list has been issued by the Ministry of Environmental Protection of China as an appendix of the Technical Guideline for Deriving Water Quality Criteria [11].

Secondly, species with established cell lines, such as mice, rats, insects, and fish, can be selected for high-throughput assays. With the existing cell lines, the ecotoxicity testing and risk evaluation can be processed according to the strategy envisaged in the NRC report [1]. For species without available cell lines, a crucial step is to check if artificial cultivation techniques are established for the species. Embryos of species that can be artificially cultivated, such as shellfish, crab, and shrimp, would permit the embryo-based medium throughput toxicity tests. Embryo-based toxicity testing is slightly more expensive than the pathway-based method, yet considerably reduces the time and costs compared to the conventional testing. Through the embryo-based assays, animals are not suffering from unpleasant states, such as pain and distress.

Species that cannot be artificially bred pose a major challenge facing the high-throughput tests. Unfortunately, it is a commonly encountered scenario that a large number of species, including endangered communities, cannot be artificially produced. Those challenges may be addressed based on characteristics of different compounds. For example, for endocrine disruptors that induce interference effects by binding to receptors, it is possible to set up regression analysis between the binding affinity and interference effects. In this case, the binding affinity of chemicals acts as an indicator to clarify the toxicity of endocrine disruptors. For another example, Yang et al. [12] derived a water quality threshold for ammonia using an eco-genomic approach. This approach based on the change of zooplankton's genetic diversity along with concentrations of ammonia, provided insight into the deployment of bioinformatics techniques in chemical risk assessment. In summary, for sensitive taxa that cannot be artificially cultivated, high-content experimental and computing methodologies 
such as molecular toxicology, systems biology, and bioinformatics, can be combined to meaningfully extrapolate ecotoxicological outcomes and devise more effective testing strategies.

Ecotoxicity data from pathway-based tests, embryo-based tests, or toxicity prediction and extrapolation modeling will ultimately be analyzed together with physicochemical properties, environmental fate, and in vivo and in vitro exposure data of chemicals. This procedure would allow a comprehensive assessment of the environmental risks posed by chemicals.

The main limitation of high-throughput assay is that endpoints measured in high-throughput assay and the assessment endpoints considered in risk assessments are not connected. Also, new tools and models are restricted by regulatory structures change [13].

Conventional toxicity testing for health and environmental risk assessments involve the use of a large number of animals, with each being labor-intensive and time-consuming. With the vision of toxicity testing in the 21st century, we hope to establish high-efficiency ecotoxicity testing strategies in future studies. The accomplishment of this goal provides supports in filling the gaps in environmental protection with big data. It is also in line with animal welfare and ethical grounds.

Author Contributions: Conceptualization, Z.-g.Y. and X.Z.; Methodology, Z.-g.Y.; Investigation, F.G.; S.-p.W.; Writing-Original Draft Preparation, Z.-g.Y.; Writing-Review \& Editing, X.Z.; J.-t.F.; L.-x.Y.

Funding: This study was supported by the Major Science and Technology Program for Water Pollution Control and Treatment (2017ZX07301002-01).

Acknowledgments: Authors thank Huan Qi He for her help with the paper polishing.

Conflicts of Interest: The authors declare no conflict of interest.

\section{References}

1. Krewski, D.; Acosta, D., Jr.; Andersen, M.; Anderson, H.; Bailar, J.C., III; Boekelheide, K.; Brent, R.; Charnley, G.; Cheung, V.G.; Green, S., Jr.; et al. Toxicity testing in the 21st century: A vision and strategy. J. Toxicol. Environ. Health B Crit. Rev. 2010, 13, 51-138. [CrossRef] [PubMed]

2. Basketter, D.A.; Clewell, H.; Kimber, I.; Rossi, A.; Blaauboer, B.; Burrier, R.; Daneshian, M.; Eskes, C.; Goldberg, A.; Hasiwa, N.; et al. A roadmap for the development of alternative (non-animal) methods for systemic toxicity testing-t4 report. Altex 2012, 29, 3-91. [CrossRef] [PubMed]

3. Xia, P.; Zhang, X.W.; Xie, Y.W.; Guan, M.; Villeneuve, D.L.; Yu, H.X. Functional toxicogenomic assessment of triclosan in human HepG2 cells using genome-wide CRISPR-Cas9 screening. Environ. Sci. Technol. 2016, 50, 10682-10692. [CrossRef] [PubMed]

4. Cairns, J. The Myth of the Most Sensitive Species. Bioscience 1986, 36, 670-672. [CrossRef]

5. Wang, X.N.; Zheng, X.; Yan, Z.G.; Liu, Z.T. Screening of native fishes for deriving aquatic life criteria. Res. Environ. Sci. 2014, 27, 341-348.

6. Zheng, X.; Yan, Z.G.; Wang, X.N.; Liu, Z.T. Screening of native crustaceans for deriving aquatic life criteria. Res. Environ. Sci. 2014, 27, 356-364.

7. Cai, J.; Yan, Z.G.; He, L.; Liu, Z.T. Screening of native amphibians for deriving aquatic life criteria. Res. Environ. Sci. 2014, 27, 349-355.

8. Wang, W.L.; Yan, Z.G.; Liu, Z.T.; Zheng, X. Screening of native annelids and aquatic insects for deriving aquatic life criteria. Res. Environ. Sci. 2014, 27, 365-372.

9. Qin, L.M.; Zhang, Y.H.; Cao, Y.; Yan, Z.G.; Zeng, H.H.; Liu, Z.T. Screening native freshwater molluscs for establishing aquatic life criteria. J. Agro-Environ. Sci. 2014, 33, 1791-1801.

10. Zheng, X.; Yan, Z.G.; Liu, Z.T.; Liu, T.T.; Wang, X.L.; Wu, J.Y.; Wang, W.L. Screening of native rotifers, hydra, planaria for deriving aquatic life criteria. Asian J. Ecotoxicol. 2015, 10, 225-234.

11. MEEC. Technical Guideline for Deriving Water Quality Criteria for the Protection of Freshwater Aquatic Organisms (HJ 831-2017); Appendix C: Chinese Resident Sensitive Freshwater Organisms; Ministry of Ecology and Environmental of China: Beijing, China, 2017. 
12. Yang, J.H.; Zhang, X.W.; Xie, Y.W.; Song, C.; Sun, J.Y.; Zhang, Y.; Giesy, J.P.; Yu, H.X. Ecogenomics of zooplankton reveals ecological threshold of ammonia nitrogen. Environ. Sci. Technol. 2017, 51, 3057-3064. [CrossRef] [PubMed]

13. Villeneuve, D.L.; Coady, K.; Escher, B.I.; Mihaich, E.; Murphy, C.A.; Schlekat, T.; Garcia-Reyero, N. High-Throughput Screening and Environmental Risk Assessment: State of the Science and Emerging Applications. Environ. Toxicol. Chem. 2019, 38, 12-26. [CrossRef] [PubMed] 